\title{
DESIGN OF AN ENHANCED TEMPERATURE CONTROL SYSTEM FOR NEONATAL INCUBATOR
}

\author{
Tamanna Afrin Tisa, Zinat Ara Nisha and Md. Adnan Kiber \\ Department of Applied Physics, Electronics \& Communication Engineering \\ University of Dhaka, Dhaka, Bangladesh \\ email: tisa.afrin@yahoo.com, xinat.elahi.nisha@gmail.com, ma_kiber@yahoo.com
}

\begin{abstract}
Worldwide every year over 4 million infants die within a month of birth. Of this number, 3.9 million belong to the developing world. Some $(25 \%)$ of this deaths are caused due to complications of prematurity, most often due to improper heat regulation, water loss and neonatal jaundice. An infant incubator provides stable levels of temperature, relative humidity and oxygen concentration. Temperature control system is the most important part of a baby incubator which has to be maintained around $37^{\circ} \mathrm{C}$. In the present work we have designed and developed an enhanced temperature control system incorporating a combination of Pulse Width Modulation (PWM) and simple ON-OFF control system, where thermistors have been used as temperature sensors. The range of variation of temperature against the set temperature $\left(37^{\circ} \mathrm{C}\right)$ has been found to be $1{ }^{\circ} \mathrm{C}$ which is satisfactory. A temperature monitor has been designed through a circuit network incorporating a thermistor so that the voltage output is linearly related to the temperature. This allowed the use of a simple millivoltmeter to display the temperature directly through appropriate scaling. To ensure the safety of the baby an alarm circuit was designed which provides sound alarms for personnel attention if the temperature goes beyond a specified safe range, chosen here as $26^{\circ} \mathrm{C}-38^{\circ} \mathrm{C}$. In developing countries, like Bangladesh frequent power cuts demand an uninterrupted operation of incubator and a battery back up system, which could also be powered by a solar panel, has been suggested for this purpose.
\end{abstract}

Keywords: Premature infants, Incubator, Temperature control, Pulse Width Modulation (PWM), Temperature indicator, Emergency alarm control.

\section{INTRODUCTION}

Every year, about 1 million infants in the developing world die due to prematurity complications [1]. Premature infants are born before the organs are mature enough to allow normal postnatal survival. As the premature infants are at risk to develop hypoxia, hypothermia and many other associated adverse conditions, they need special care and attention. One of the major problems that newborns face is improper thermoregulation. The temperature inside the mother's womb is $38^{\circ} \mathrm{C}\left(100.4^{\circ} \mathrm{F}\right)$. Leaving the warmth of the womb at birth, the wet new born finds itself in a much colder environment and immediately starts losing heat. In the first $10-20$ minutes, the new born who is not thermally protected may lose enough heat for the body temperature to fall by $2-4^{\circ} \mathrm{C}\left(3.6-7.2^{\circ} \mathrm{F}\right)$, with even greater falls in the following hours if proper care is not given [2,3]. If heat loss is not prevented and is allowed to continue, the baby will develop hypothermia and is at increased risk of developing health problems and of death. Therefore an infant incubator is necessary which attempts to create the necessary environment for the baby's survival [4]. This device may include an ac-powered heater, a fan to circulate the warmed air, a container for water to add humidity, a control valve for oxygen supply and access ports for nursing care.

The first incubator was developed in 1857 named warmwännaen. In 1833, Pierre-Victor-Adolph published an account of another incubator, developed by Etienne Stephane Tarnier for use of enormous Paris Maternite named couveuse. In 1891 reports came of a new incubator design in France, designed by Alexander Lion of Nice. Today developments are still constantly underway to try and create an ever more womb like environment; controlling oxygen levels and other vital systems, with an array of sensors, monitors and alarms [5]. There are different types of incubator such as Open box type incubator, Close type incubator, Manually controlled incubator, Servo controlled incubator and Transport incubator [6]. 
Temperature regulation is of primary importance in an incubator. The present work therefore focuses on the temperature control and simultaneous monitoring of an incubator. This also should have an alarm system to indicate accidental situations of failure. For uninterrupted operations, a power system based on battery back up may be used. For remote areas where mains electricity is not available, a solar panel may be used to provide necessary power. This is an important criterion that needs to be considered for incubators in developing countries like ours where frequent failure of mains supply is a regular feature.

\section{DESIGN, DEVELOPMENT AND PERFORMANCE}

The temperature of the baby incubator needs to be maintained at a constant level of $37^{\circ} \mathrm{C}$. A temperature indicator together with an alarm for accidental failures is also needed. This was the main challenge of the present work. We first designed a simple ON-OFF temperature control system which did not appear to be satisfactory. Thereafter we designed and developed an enhanced temperature control system which had a combination of a Pulse Width Modulation control and an ON-OFF temperature control system. The performance of this combined system was satisfactory. We have also designed a temperature indicator using a simple milli-voltmeter by linearizing the performance of thermistor in the range of temperature $30-40^{\circ} \mathrm{C}$. This system also incorporates high temperature $\left(38^{\circ} \mathrm{C}\right)$ and low temperature $\left(25^{\circ} \mathrm{C}\right)$ alarm for medical attention in the case of accidental failure of the temperature regulation system.

\subsection{Temperature Control System}

Temperature control system is an important integral part of a baby incubator. Selection of an appropriate temperature sensor is important for effective control of temperature in the incubator. Comparing the sensitivity and response time of available temperature sensors like thermistor, thermocouple, RTD in the range of temperature $25-40^{\circ} \mathrm{C}$ along with accuracy, repeatability, term stability, linearity, self heating; thermistor is the best choice in this case $[7,8]$.

If the temperature falls below the set value appropriate amount of heat energy needs to be supplied in the incubator to maintain the temperature at that level. This can be done by a simple turn ON and OFF control system which will turn ON the heater when the temperature is below the set level and turn OFF otherwise.

\subsubsection{Simple ON-OFF Control System}

Block diagram of a simple ON-OFF control circuit is given below in Fig. 1.

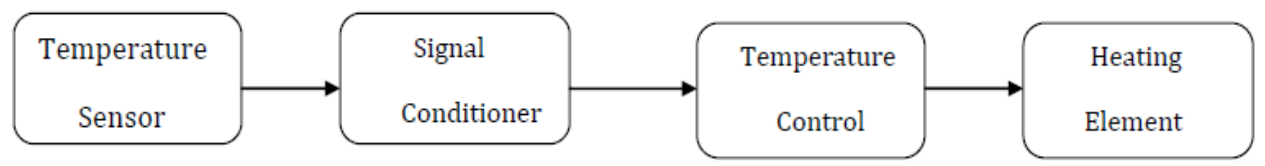

Fig. 1: Block diagram of simple ON-OFF control circuit

To improve the temperature sensitivity of the system, the thermistor was placed in one arm $\left(R_{2}\right)$ of a Wheatstone bridge, as shown in Fig. 2, rather than in a voltage divider circuit. Firstly a balance is obtained through adjustments of the resistors in the other arms $\left(R_{1} / R_{3}=R_{2} / R_{4}\right)$. The unbalanced output voltage of the bridge as shown was used to give a measure of the temperature change. It is well known that this sensitivity is the greatest when $R_{2}$ is almost equal to $R_{4}$ [9]. So, the selection of the value of $R_{1}, R_{2}$ and $R_{3}$ depends on the resistance of the thermistor. To select the value of the resistance now we need to know the response of the thermistor that is to be used with the change in temperature. Fig. 3 shows a graph of the resistance of a $4.7 \mathrm{k} \Omega$ thermistor with temperature. 


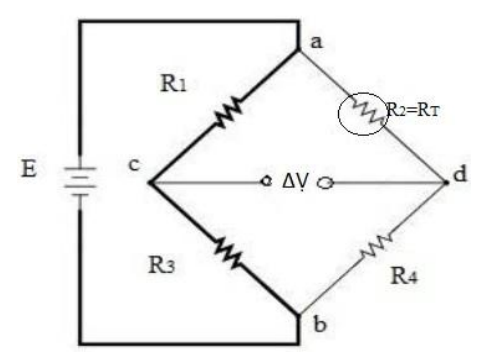

Fig. 2: Wheatstone bridge circuit.

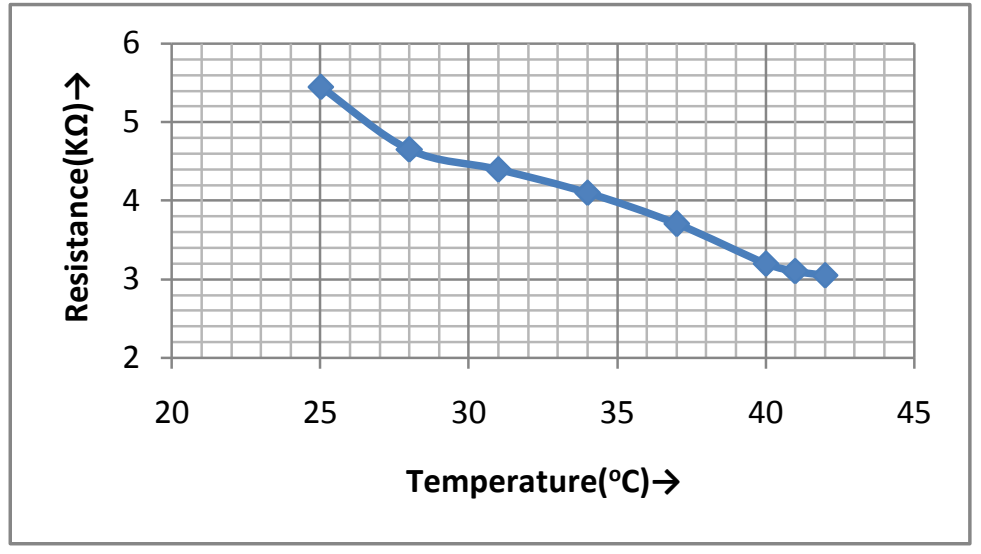

Fig. 3: Resistance Characteristic of $4.7 \mathrm{~K} \Omega$ NTC Thermistor

It can be seen that the resistance of the thermistor changes between $4.4 \mathrm{~K} \Omega-3.2 \mathrm{~K} \Omega$ in the range of temperature between $31-40^{\circ} \mathrm{C}$. The average resistance in that range is $3.85 \mathrm{~K} \Omega$. A resistor of this value is not practically available so we have used $4 \mathrm{~K} \Omega$ in the bridge circuit for $\mathrm{R}_{2}$.

The circuitry developed and a graphical response for the simple ON-OFF control system are given in Fig. 4 (a \& b).

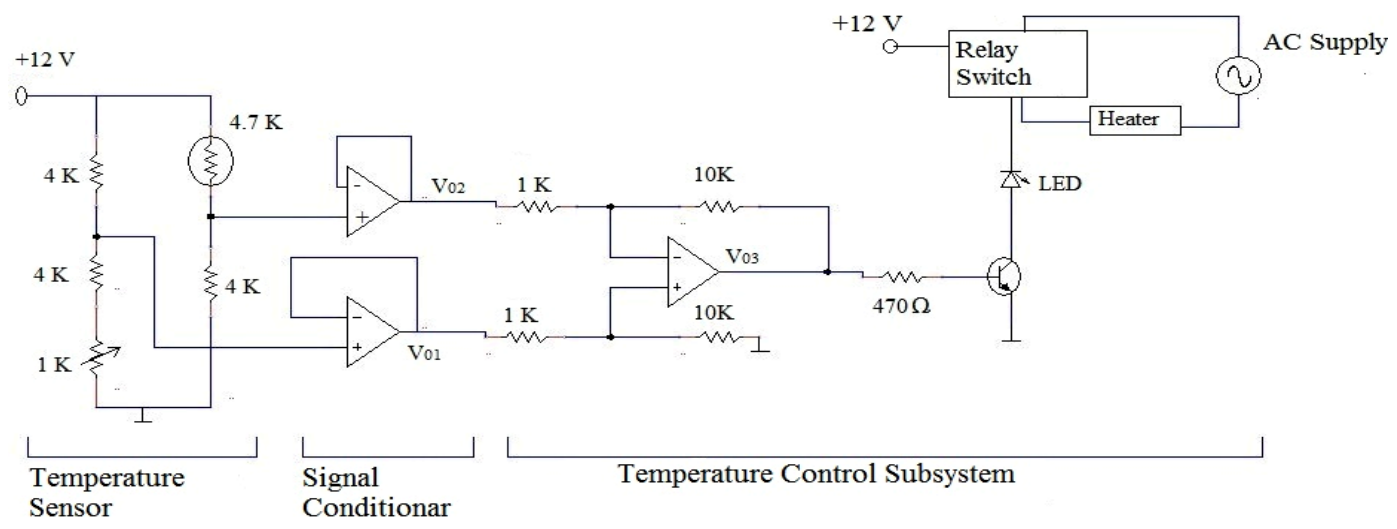

Fig. 4: (a) A Simple ON-OFF control circuit

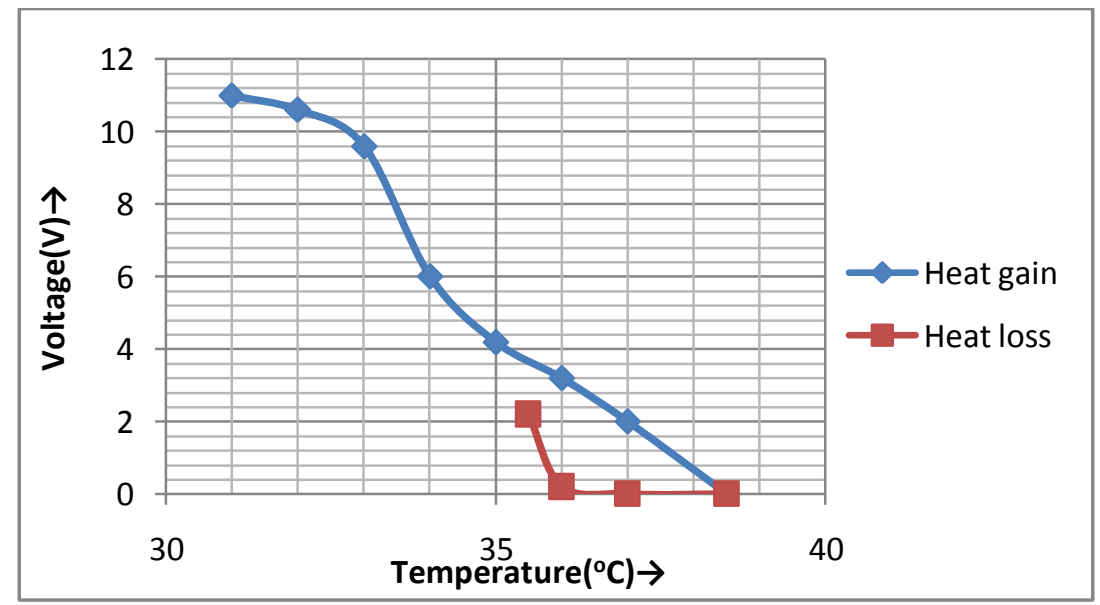

Fig. 4(b) Temperature response graph 
From Fig. 4(b) it is seen that during the heating cycle (blue line), the heater was fully ON until the temperature reached $38.5^{\circ} \mathrm{C}$ and during the cooling cycle (red line) the heater was not turned $\mathrm{ON}$ until the temperature was $35.5^{\circ} \mathrm{C}$. Ideally, it is expected that the heater should turn ON and OFF at the specified temperature which is $37^{\circ} \mathrm{C}$. The graph shows that the range of temperature swing was $3{ }^{\circ} \mathrm{C}$ which is not satisfactory for an incubator. Therefore, we designed a modified temperature control system using a Pulse Width Modulation (PWM) control system where we can control the duty cycle of the heater.

\subsubsection{Temperature Control System using Pulse Width Modulation (PWM)}

To construct a simple PWM control system we have used two integrated 555 timers as shown in Fig.5. The right hand part of the circuit in Fig.5 is a monostable circuit whose timing is controlled by a Thermistor so that the pulse width decreases with temperature. The left hand part of the circuit in Fig. 5 is an astable circuit running at a frequency of $100 \mathrm{~Hz}$ which triggers the monostable circuit to produce a train of pulses whose width is modulated by temperature.
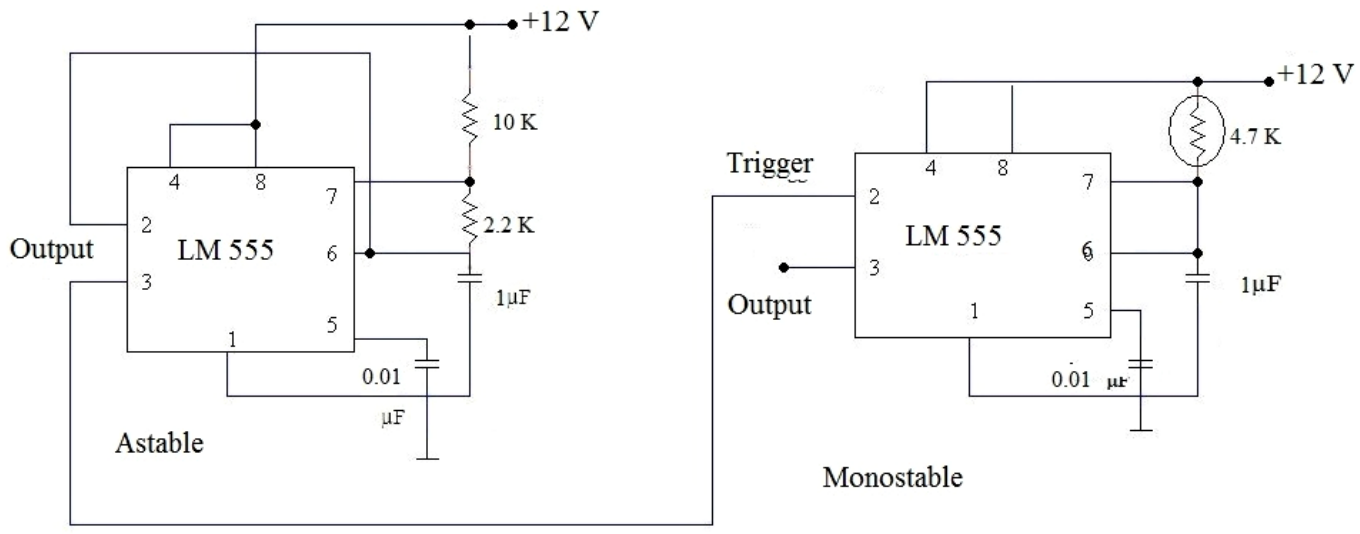

Monostable

Fig. 5: Circuit diagram of advanced PWM control unit

Here, the frequency of oscillation is $f=\frac{1}{T}=\frac{1.44}{\left(R_{A}+2 R_{B}\right) C}$

To get a frequency of $100 \mathrm{~Hz}$ the values of the resistances and capacitor were chosen as:

$\mathrm{R}_{\mathrm{A}}=10 \mathrm{~K} \Omega, \mathrm{R}_{\mathrm{B}}=2.2 \mathrm{~K} \Omega$ and $\mathrm{C}=1 \mu \mathrm{F}$

The pulse width of the monostable circuit is given by, $T_{H}=1.1 R_{T} C_{T}$ where $\mathrm{R}_{\mathrm{T}}$ is the resistance of the thermistor and $\mathrm{C}_{\mathrm{T}}$ is the timing capacitor of this circuit.

Therefore, the duty cycle of the PWM signal is given by, $\mathrm{T}_{\mathrm{H}} / \mathrm{T}$

The duty cycle variation as a function of temperature for PWM Control Unit is shown in Fig.6. It can be seen that the duty cycle is about $37 \%$ at the set temperature of $37^{\circ} \mathrm{C}$. There will always be a finite non-zero resistance of the thermistor. Therefore, the duty cycle cannot be made zero. This means that the incubator will still continue to be heated further.

So, we need another control system in addition to this PWM control to completely switch OFF the heater at the set temperature. The new advanced control system which is a combination of PWM and simple ON-OFF control system is described now. 


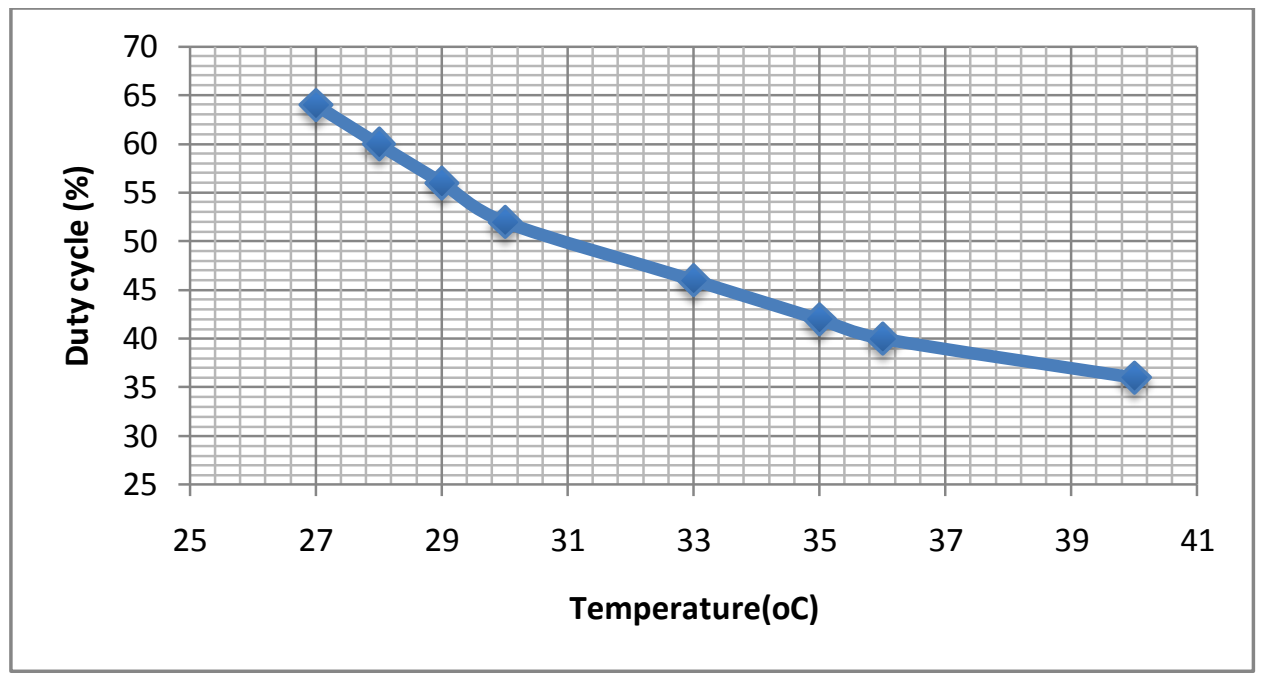

Fig. 6: Duty cycle variation as a function of temperature for PWM Control Unit

\subsubsection{Combined Enhanced Temperature Control System}

The block diagram of the combined enhanced temperature control system is shown in Fig.7.

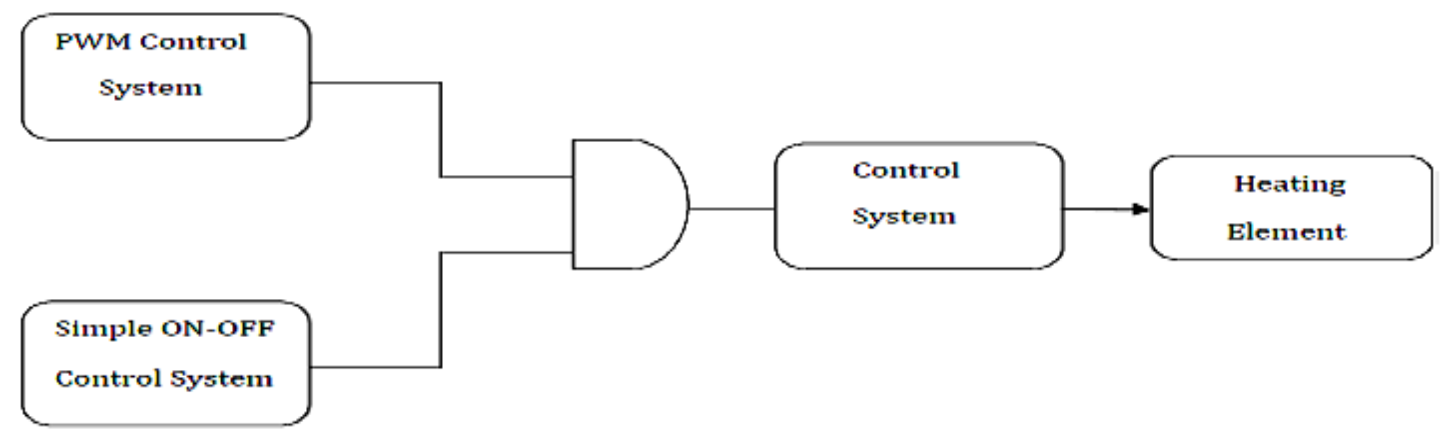

Fig.7: Block diagram of the combined enhanced temperature control system

As long as the output of the Simple ON-OFF circuit is high the output of the AND gate follows the PWM. So, the duty cycle of the heater or the amount of heat energy delivered is controlled by the output of the PWM, tapering off to a low value near $37^{\circ} \mathrm{C}$. When the temperature reaches the set temperature the output of the simple ON-OFF control circuit becomes zero which forces the output of the AND gate to zero and overrides the PWM. So, it finally shuts down the heater at the set temperature $\left(37^{\circ} \mathrm{C}\right)$. However, the temperature overshoots a little due to thermal inertia, but because of the reduced heating before switching off the overshoot is much less than that encountered in a simple ON-OFF system described before. The complete circuit diagram of this combined enhanced temperature control system is shown in Fig.8.

The performance of the combined ON-OFF \& PWM temperature control system (enhanced control system) is shown in Fig.9. Once the temperature reaches the set value it remains almost constant, varying within a maximum and minimum of $37.5^{\circ} \mathrm{C}$ and $36.5^{\circ} \mathrm{C}$, giving a maximum range of variation of temperature of $1{ }^{\circ} \mathrm{C}$. This is a reasonable range from a practical point of view. 


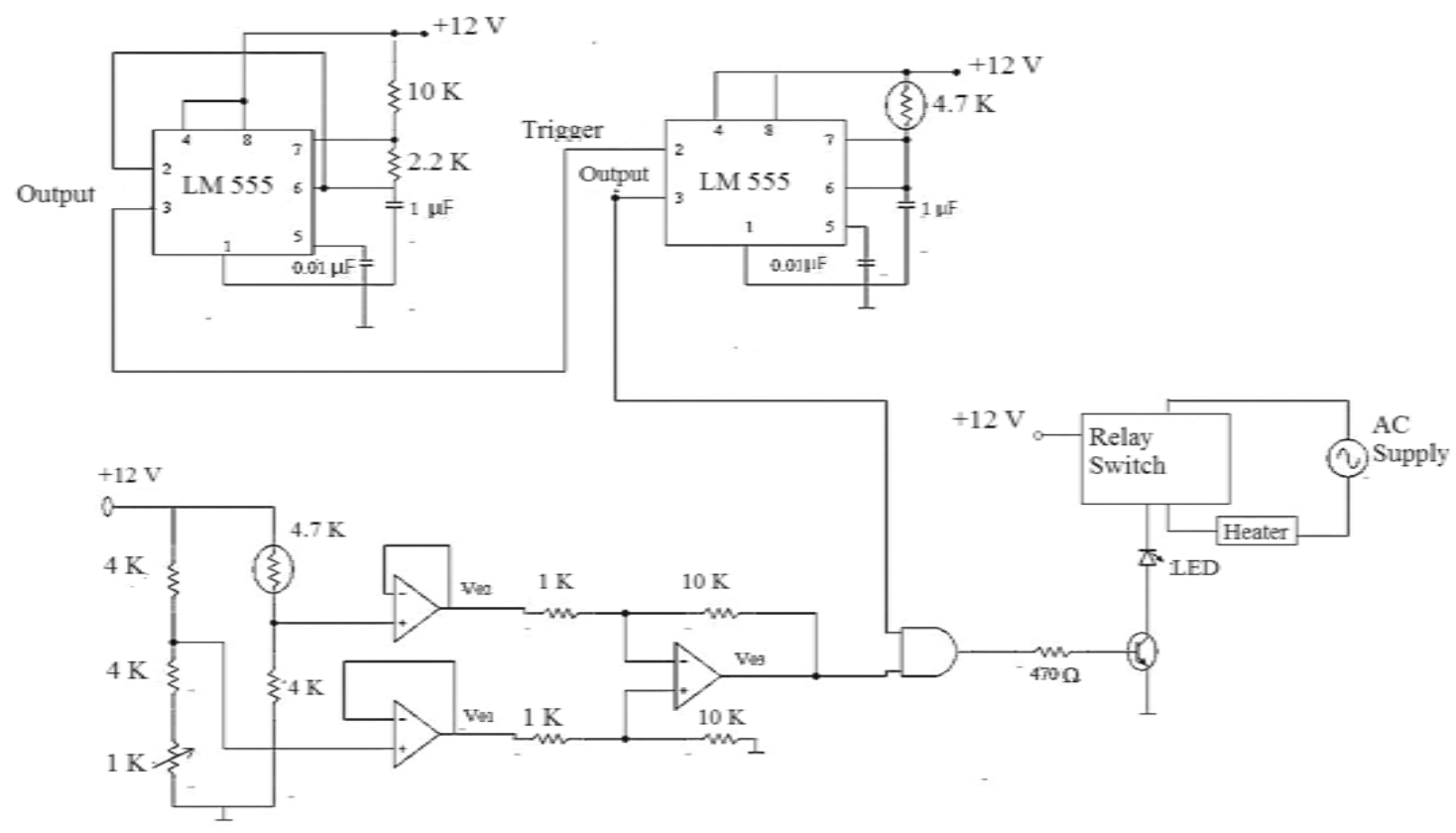

Fig. 8: Circuit diagram of a combined enhanced temperature control system.

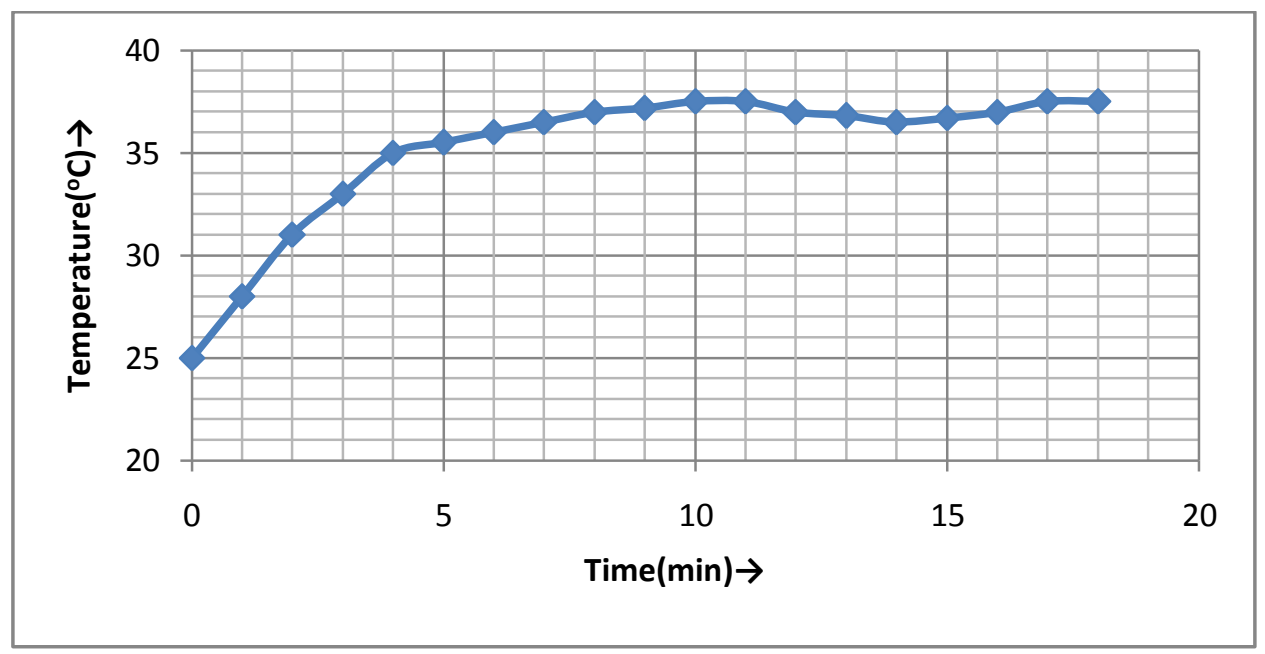

Fig. 9: Temperature variation as a function of time for the combined enhanced control unit.

\subsection{Temperature Indicator}

To monitor the temperature at the bed level of the incubator a temperature indicator was designed using a thermistor and the output displayed using a simple milli-voltmeter. This demands the resistance-temperature characteristics to be linear but unfortunately the response of a thermistor is nonlinear. One approach to make the response of a thermistor linear is simply shunting it with a fixed resistor $[8,9]$. The primary disadvantage to this technique is that linearization can only be achieved within a narrow range. A simple analysis based on parallel combination of resistors led to value of about $840 \Omega$ for the fixed resistance. The practical response is shown in Fig. 10. 


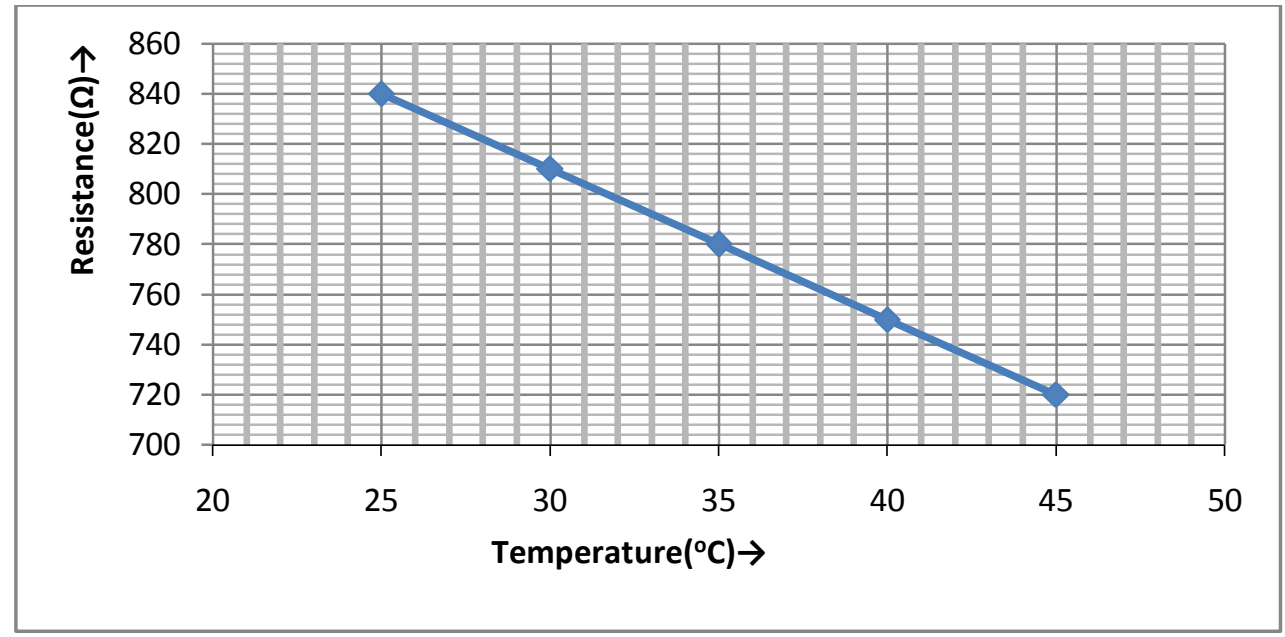

Fig. 10: Linearization of NTC Thermistor using $840 \Omega$ as a Shunt Resistor.

The circuit developed and the response for the temperature indication are shown in Fig.11.

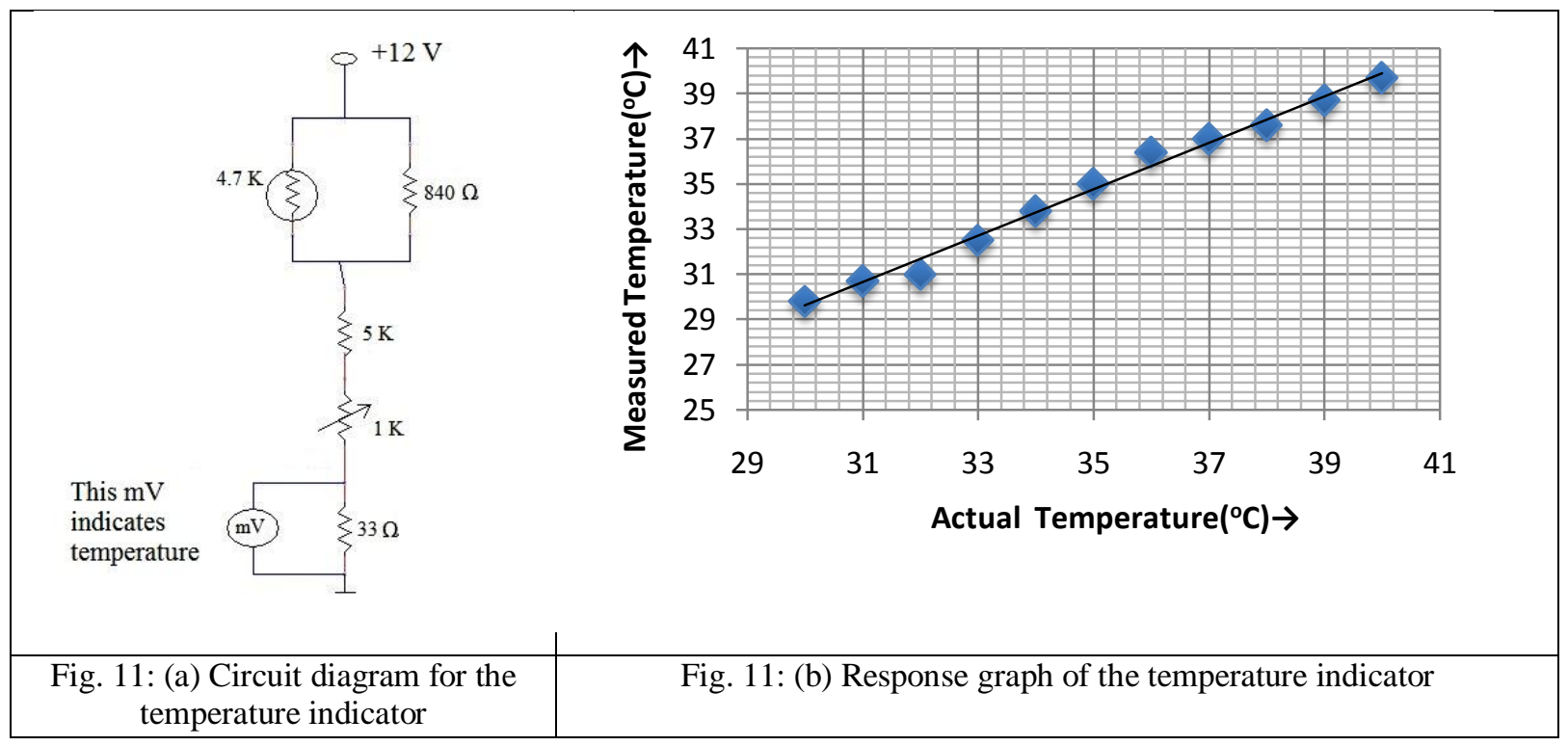

From the graph of the temperature indicator shown in Fig. 11(b) it can be seen that an actual temperature of $37^{\circ} \mathrm{C}$ is indicated as $37.2^{\circ} \mathrm{C}$ which is acceptable for this application.

\subsection{Alarm Control System}

An alarm circuit is safety measure to ensure the safety of the baby, by calling the attention of medical personnel, whenever the system fails, or crossed the set limits.

Here, we have designed an alarm control circuit which will provide high temperature indication when the temperature of the incubator exceeds $38^{\circ} \mathrm{C}$, and also provides low temperature indication when temperature of incubator is below $25^{\circ} \mathrm{C}$ and in both case it will produce loud sound from the speaker for medical attention.

The complete circuit diagram of designed alarm control system is shown in Fig.12 


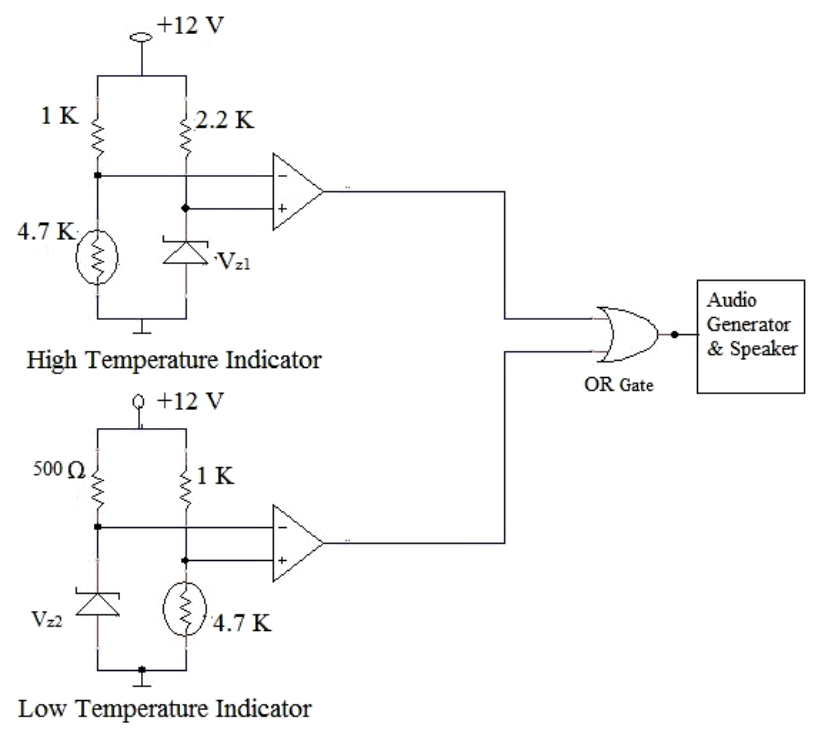

Fig. 12: Circuit diagram of designed alarm control system

To sense the high temperature we have used a $3.6 \mathrm{~V}$ zener diode for reference while for the low temperature we have used a $5.5 \mathrm{~V}$ zener diode. This alarm control unit practically gave indication when the temperature increased beyond $38.5^{\circ} \mathrm{C}$ or fell below $26^{\circ} \mathrm{C}$, producing a loud sound from the speaker for medical attention.

\section{DISCUSSION}

An incubator plays a vital role in saving premature babies. One of the main functions of infant incubator is temperature control which is required to achieve thermo-neutrality in infant's body. To serve this purpose we have designed a simple ON-OFF control circuit which will maintain the temperature of the incubator at a desired level $\left(37^{0} \mathrm{C}\right)$. But there is a $3^{0} \mathrm{C}$ swing in temperature range against the set value. This could be due to the fact that, it takes time for the distribution of heat energy from the heater to the surroundings and there is a lag of response time for the temperature sensor to respond to the change in temperature. To overcome this problem an enhanced regulation system was developed based on a combination of a PWM circuit and an ON-OFF circuitry. The PWM circuit tapers off the energy supplied to heat the incubator as the temperature rises to $37^{\circ} \mathrm{C}$. This reduces the thermal inertia when the heating circuit is then switched off. The temperature increased by only $0.5^{\circ} \mathrm{C}$, i.e., to $37.5^{\circ} \mathrm{C}$ which is an acceptable value. While the incubator cooled off, the heater switched on again at $36.5^{\circ} \mathrm{C}$. Thus using the enhanced control system, the temperature swing was only $1^{\circ} \mathrm{C}$, which is satisfactory and acceptable for a neonatal incubator.

The linearization circuit made for the thermistor gave a satisfactory performance as can be seen through the measured values in the graphs. The linearity was good for the temperature range of $30^{\circ} \mathrm{C}$ $40^{\circ} \mathrm{C}$ which is acceptable for this application too. This allowed monitoring of the temperature directly using a simple millivoltmeter through appropriate voltage adjustment. The alarm circuit designed worked satisfactorily too. This produced a loud sound alarm to draw the attention of medical attendants if the temperature went above $38^{\circ} \mathrm{C}$ or went below $26^{\circ} \mathrm{C}$.

In developing countries like ours frequent power cut occurs, it needs to be addressed for continuous operation of the incubator. A battery back up has been suggested to operate the incubator under such situations. A solar panel may also be used to provide the necessary power. Thus the present work paves the way to design and develop a complete incubator that could save lives in rural areas of developing countries like Bangladesh. 


\section{REFERENCES}

1. World Health Report 1998; Life in the 21st century: A vision for all

2. “Thermoregulation", Thermolugation_final_5.4.98.pdf

3. World Health Organization, Maternal or newborn health/ Safe motherhood unit, Division of reproductive health (Technical Support) "Thermal Protection of newborn: a practical guide", Geneva, (WHO/RHT/MSM/1997, 2nd Edition).

4. Guler* and M. Burunkaya, "Humidity control of an incubator using the microcontrollerbased active humidifier system employing an ultrasonic nebulizer", J of Medical Engineering \& Technology, Vol. 26, No.2, 2002, p.82- 88.

5. Katie Proctor, "Transferring the incubator: Fairs and freaks shows as agents of change", 2004. www.people.cornell.edu/pages/ked42/Infant_Sideshow_Paper.pdf. (WHO/RHT/MSM/1997, 2nd Ed).

6. Emergency Care Research Institute (ECRI), "Healthcare Product Comparison System - Infant Incubators", February 2003, www.ecri.org.

7. Albert D. Helfrick \& William D. Cooper, Modern Electronics Instrumentation and Measurement Techniques. P.337-370.

8. B.L.Theraja, Basic Electronics Solid State. P. 564-575.

9. <research.cs.tamu.edu/prism/lectures/iss/iss-14.pdf> 
